International Journal of Trend in Scientific Research and Development (IJTSRD)

Volume: 3 | Issue: 3 | Mar-Apr 2019 Available Online: www.ijtsrd.com e-ISSN: 2456 - 6470

\title{
Evaluation of Porosity in Fusion Welded AA2014 Plates using X-Ray Radiography
}

\author{
Mr. N. Nagendra Kumar1, R. Akshay², P. Durga Kishore², V. Sai Kiran² \\ ${ }^{1}$ Assistant Professor, ${ }^{2}$ Student \\ ${ }_{1,2}$ Department of Mechanical Engineering, Guru Nanak Institute of Technology, Hyderabad, India
}

\begin{abstract}
How to cite this paper: Mr. N. Nagendra Kumar | R. Akshay | P. Durga Kishore | V. Sai Kiran "Evaluation of Porosity in Fusion Welded AA2014 Plates using XRay Radiography" Published in International Journal of Trend in Scientific Research and Development (ijtsrd), ISSN: 24566470, Volume-3 | Issue-3 , April 2019, pp.1027-1031, URL: https://www.ijtsrd.c om/papers/ijtsrd23 186.pdf

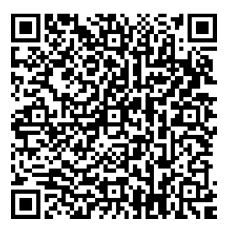
IITSRD23186
\end{abstract}

Copyright (C) 2019 by author(s) and International Journal of Trend in Scientific Research and Development Journal. This is an Open Access article distributed under the terms of the Creative Commons

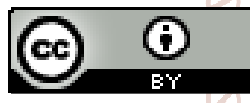
Attribution License (CC BY 4.0) (http://creativecommons.org/licenses/ by $/ 4.0$ )

\section{INTRODUCTION}

Aluminum Alloy AA (2014)

Aluminum Alloy AA (2014) is a copper-based alloy with very high strength together with excellent machining characteristics. Alloy 2014 is commonly used in many aerospace structural applications due to its high strength. Other applications include military vehicles, bridges, weapons manufacture and structural applications. The aerospace industry demands a lot from the materials it uses. Demands include improved toughness, lower weight, increased resistance to fatigue and corrosion. The boundaries of material properties are being constantly extended as manufacturers strive to give the next generation of aircraft improved performance while making them more efficient. Aluminum is one of the key materials facing these challenges. Aluminum alloy plate is used in a large number of aerospace applications, ranging in complexity and performance requirements from simple components through to primary load bearing structures in aircraft

\section{ABSTAC}

NDT has evolved as an essentialdemand in much modern engineering design in ortant to the end use of the object being inspected. Failure is the primary the integrity, safety and performance of aircraft structure. The aero grase the form of plate and done on this material Penetrant testing for to reveal surface defects, Ultrasonic testing to detect the subsurface and internal defects, X-Ray Radiography for internal defects. Apart from conventional methods, remote crack inspection was analysed. The acoustic emission test was conducted for the calibration of equipment for testing of AA (2014) material. Surface defects were detected by penetrant testing and internal defects like inclusions, blow holes, porosity and

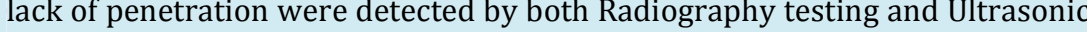
tests. Very fine porosity was detected by ultrasonic phased array method, which could not be detected by Radiography testing and Ultrasonic testing.

\section{KEYWORDS: X-Ray Radiography, porosity, TIG-Welding and AA2014 plates}

\section{Chemical Composition} \begin{tabular}{|l|l|}
\hline Elements & Percentage (\%) \\
\hline
\end{tabular}

\begin{tabular}{|c|c|}
\hline $\mathrm{Cu}$ & $3.8-5$ \\
\hline $\mathrm{Mg}$ & $0.2-0.8$ \\
\hline $\mathrm{Si}$ & $0.5-1.2$ \\
\hline $\mathrm{Fe}$ & 0.7 \\
\hline $\mathrm{Mn}$ & $0.3-1.2$ \\
\hline Others & 1.5 \\
\hline
\end{tabular}

Table Chemical Composition

Mechanical properties

\begin{tabular}{|c|c|}
\hline Hardness, Brinell & 135 \\
\hline Hardness, Knoop & 170 \\
\hline Hardness, Rockwell A & 50.5 \\
\hline Hardness, Rockwell B & 82 \\
\hline Hardness, Vickers & 155 \\
\hline Ultimate tensile Strength & $483 \mathrm{MPa}$ \\
\hline Tensile Yield Strength & $414 \mathrm{MPa}$ \\
\hline Modulus of elasticity & $72.4 \mathrm{GPa}$ \\
\hline \multicolumn{2}{|c|}{ Table Mechanical Properties }
\end{tabular}

GAS TUNGSTEN ARC WELDING

Gas Tungsten Arc Welding (GTAW) is referred to in professional circles as Tungsten Inert Gas (TIG) welding. This is an arc welding process that uses a tungsten electrode to create the weld. Learning the fundamentals of GTAW will 
certainly enlarge the welder's work skills. Gas tungsten arc welding (GTAW) is an electric arc welding process that produces an arc between a non-consumable electrode and the work to be welded. To qualify as a GTAW welder, you need to learn and gain proficiency in welding joints, corners, and $\mathrm{T}$ (fillet). Each of these types call for different considerations of GTAW and the welder must understand the varying methods. It is possible to configure all three joint types with mild steel, stainless steel, and aluminum provided the special precautions for each type of metal is followed. As a common rule, before commencing welding on any joint of any material, clean the material properly and position the GTAW torch at a 70-degree angle to the seam of the joint, with the filler metal at a 20-degree angle to the joint. Make it a point to use a high-frequency start for DC work on mild steel and stainless steel, and use continuous high frequency for AC aluminum applications. GTAW is capable of being used on both ferrous and nonferrous metals and depending on the base metal, in all welding positions. When welding thinner materials, edge joints, and flange, filler metals are not needed. For thicker materials, however, an externally fed filler wire is generally used. The type of filler metal wire to be used is based on the chemical analysis of the base metal. The size of the filler metal wire varies depending on the thickness of the base metal.

The procedure for welding butt joints of carbon and stainless steel is they should be tack welded or skip welded - weld an inch, move down several inches and weld another inch, until you reach the end of the joint. Thereafter do the welding between the existing welds. As aluminum does not distort as much as stainless steel, the tacks can be placed farther apart maybe at three inches.

T joints, as we know, consist of two pieces of material connecting each other at right angle. They need a fillet weld and are widely seen in many fabrications of building industry. T Joint in a tube requires a curved fillet weld as the connecting tube contours to the curve of the crossmember of the T. For T joints, you must place the weld on the same side of the joint where force against the weld will be applied.

A corner joint consists of two pieces of material joined to form an L shape. These are of two types. When the edge of one piece lies flush against the edge of the other piece, it is a closed corner joint. When two edges meet at their corners and there is an opening then it is an open corner joint. You usually can fusion weld a closed corner joint without adding filler metal.

Open corner welds however, needs filler metal.

It may be stated that there are many things in common with regard to Corner, butt, and T Joints. But there also many differences amongst them. There are five basic types of joints and they are the butt joint, the corner joint, the edge joint, the lap joint, and the tee joint. Of the five types of joint designs, the butt and the tee joint are the most common.

\section{RADIOGRAPHY INSPECTION}

Radiography is used to detect the features of a component or assembly that exhibit a difference in thickness or physical density as compared to surrounding material. Large differences are more easily detected than small ones. In general, radiography can detect only those features that have an appreciable thickness in a direction parallel to the radiation beam. This means that the ability of the process to detect planar discontinuities such as cracks depends on proper orientation of the test piece during inspection. Discontinuities such as voids and inclusions, which have measurable thickness in all directions, can be detected as long as they are not too small in relation to section thickness. In general, features that exhibit a $1 \%$ or more difference in absorption compared to the surrounding material can be detected.

Although neither is limited to the detection of internal flaws, radiography and ultrasonic's are the two generally used Non Destructive inspection methods that can satisfactorily detect flaws that are internal and located well below the surface of the part. Neither method is limited to the detection of specific types of internal flaws, but radiography is more effective when the flaws are not planar, In comparison to other generally used Non Destructive methods, radiography has three main advantages:

$>$ The ability to detect internal flaws

$>$ The ability to detect significant variations in composition

$>$ Permanent recording of raw inspection data

\section{PRINCIPLES OF RADIOGRAPHY}

Three basic elements of radiography include a radiation source, the test piece or object being evaluated, and a sensing material. These elements are shown schematically in Fig. 1. The test piece in Fig. is a plate of uniform thickness containing an internal flaw that has absorption characteristics different from those of the surrounding material. Radiation from the source is absorbed by the test piece as the radiation passes through it; the flaw and surrounding material absorb different amounts of radiation. Thus, the intensity of radiation that impinges on the sensing material in the area beneath the flaw is different from the amount that impinges on adjacent areas. This produces an image, or shadow, of the flaw on the sensing material. This section briefly reviews the general characteristics and safety principles associated with radiography.

X-ray and gamma rays differ only in their source of origin. An $\mathrm{X}$-ray generator produces $\mathrm{X}$-rays and gamma radiation is the product of radioactive atoms. They are both part of the electromagnetic spectrum. They are waveforms as are light rays, microwaves, and radio waves. X-rays and gamma rays cannot be seen, felt or heard. They posses no charge and no mass and, therefore they are not influenced by electrical and magnetic fields and will generally travel in straight lines. However, they can be diffracted in a manner similar to light. Both X-rays and gamma rays can be characterized by frequency, wavelength, and velocity. However, they act somewhat like a particle at times in that they occur as small "packets" of energy and are referred to as PHOTONS. Electromagnetic radiation has also been described in terms of a steam of photons each travelling in a wave-like patterns and moving at the speed of light.

Each photon contains a certain amount of energy, and all electromagnetic radiation consists of these photons. The only difference in between the various types of electromagnetic radiation is the amount of energy found in the photon. Due to their short wavelength, they have more energy to pass through matter than do the other forms of energy in the electromagnetic spectrum. As they pass through matter, they are scattered and absorbed and the 
degree of penetration depends on the kind of matter and the energy of rays.

\section{X-Ray Method}

X-rays are invisible electromagnetic radiation of very short wavelength, which will travel in straightlines. The operation of cathode ray tube produced fluorescence in a barium platinum cyanide screen placed at some distance from the tube. Thus roentgen felt due to emission of some very penetrating rays from cathode ray tube they called them Xrays, these rays are also called as roentgen rays.

\section{Principle}

Clausius 2 principle, which states that whenever accelerated changed particles are deaccelerated X-rays are produced.

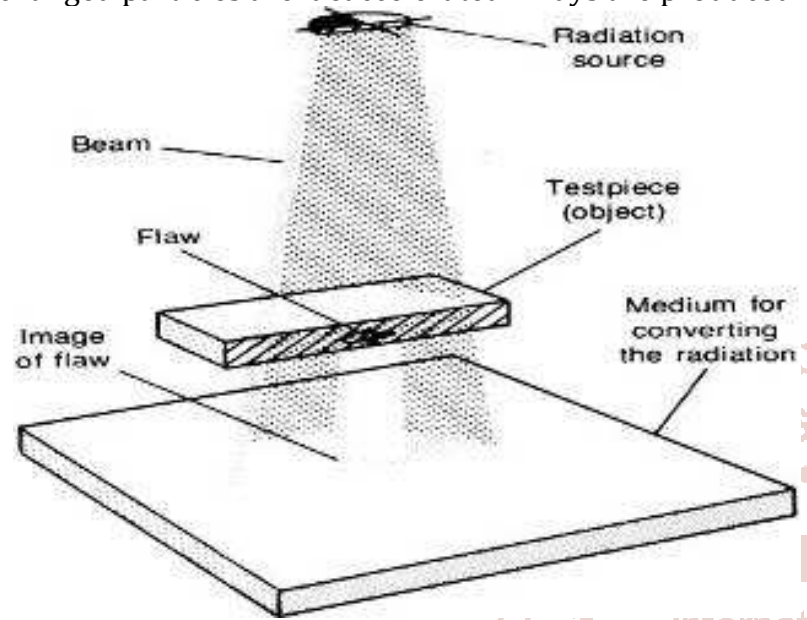

Fig. Schematic of the basic elements of a radiographic system

A. Classification of X-Rays

1. Characteristic (or) Monochromatic X-rays: All X-rays produced have same Wavelength (first Orbit electrons).

2. Continuous X-rays: X-rays produced are having different wavelength. Energy distribution depends on Potential Difference across the X-ray tube. More energy appears in the spectrum, as the potential difference is increase. As potential difference increases, the lower wavelength limit falls. The wavelength limit appears to be independent of the metal used as the target.

\section{B. Properties of X-Rays}

$>$ They are not detected by human senses

$>$ They travel in straight lines at the speed of light.

$>$ Their paths cannot be changed by electrical or magnetic fields.

$>$ They can be diffracted to small degree at interfaces between two different materials.

$>$ They pass through matter until they have a chance encounter with an atomic particle.

$>$ Their degree of penetration depends on their energy and the matter they are travelling through.

$>$ They have enough energy to ionize matter and can damage or destroy living cells.

\section{Production of X-Rays}

$\mathrm{X}$-rays are produced when a beam of high-energy electrons collides with any material or target or when fast moving electrons are suddenly stopped by a target suddenly part of the energy is converted into X-rays and part of the energy is converted into heat. X-ray production increases with the increase in atomic number of the target atom and with the increase in the incident electron energy. In X-rays machine, less than $1 \%$ of electrical power supplied is converted to $\mathrm{X}$ rays and the remaining power is converted into heat energy by the target. If the heat is not removed efficiently, the target material may melt. In an X-ray machine if the potential difference between the filament and the target are the applied Kilo Voltage is $200 \mathrm{KV}$ then the electrons, striking the target is 200 Kevin the maximum energy of X-rays would be $200 \mathrm{keV}$. The target is usually of small dimension, say $1 / 5$ $3 \mathrm{~mm}$. And the electrons hit the target much of the energy appears in the form of heat and it has to be rapidly removed.

Electrons move from cathode to anode. The potential difference between anode and cathode will be $120 \mathrm{KV}$. When fast-moving electrons will hit the target, this energy is transferred into X-rays. Filter will absorb the higher wavelength rays and lower penetrating capability. For controlling Quality (Intensity) and quantity, we need to control the controls or control unit.

]

\section{$>$ Image Quality Indicators}

The quality of radiograph or sensitivity of process is expressed in terms of image quality indicators or pentameters sensitivity. These are small devices placed on the surface of the specimen during expression and visibility of their image on the radiograph forms the criteria of sensitivity. Image quality indicators are of simple geometric form and made up of same or radiographically similar materials as the specimen being examined. The image of the IQI on the film. Radiograph is permanent evidence that the radiographic examination was conducted with proper procedure or condition.

1. Material should be preferable be the same as that of he inspected.

2. It must be sensitive in its readings to changes to radiographic technique.

3. Method of recording should be simple unambiguous.

4. It should mean for identification.

\section{A. Plaque hole Type Penetrameter}

The widely used American Penetrameter are those that follow the ASTM and ASME recommended designs. This consists of a plate of uniform thickness in which three drilled holes of diameters equal to $1 \mathrm{~T}, 2 \mathrm{~T} \& 4 \mathrm{~T}$ are made. The thickness of each pentameter is fashioned on the levels of sensitivity desired. A $1 \%$ Penetrameter is one in which the thickness of Penetrameter correspond to $1 \%$ of the specimen thickness, a $2 \%$ Penetrameter is the one which has $2 \%$ of the specimen thickness.

\section{B. Wire Type Penetrameter}

Wire type Penetrameter consist of a series of wire minimum length of $25 \mathrm{~mm}$ mounted side by side parallel with a distance between the axis of wire if not less than three times the wire diameter and not less than $\mathrm{mm}$. The wires are made of also steel of material radiographically similar to that of object under inspection. Wire type having different wires of different thickness.

\section{DIN Type}

The wires are made of aluminum or steel or of material similar to that of object under inspection. The DIN are graded in geometrical progression with designation from 116 , the first number wire having diameter $3.2 \mathrm{~mm}$ and the $16^{\text {th }}$ wire having $0.10 \mathrm{~mm}$. Each wire is about $5 \mathrm{~cm}$ long. The ratio between the thickness of adjacent wires is $1.25 \mathrm{~mm}$. 


\section{ASTM Type:}

The design consists of 4 sets of wires having diameters from $0.0032 \mathrm{~mm}$ to $1.32 \mathrm{~mm}$. each set has 6 wire of the previous set repeated as the $1^{\text {st }}$ wire of the next set. The Penetrameter design is characterized by its simplicity, ease of application and independence to beam orientation. The design accounts for, to some extent, definition or unharness and contract factors, particularly related to linear volume elements. There is no defined relationship that exists between the sensitivity levels obtained by wire types and plaque hole type Penetrameter.

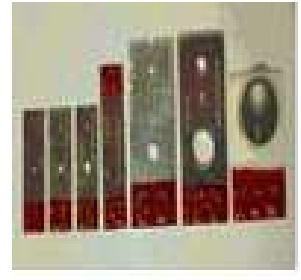

(a)

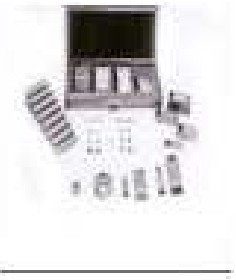

(b)

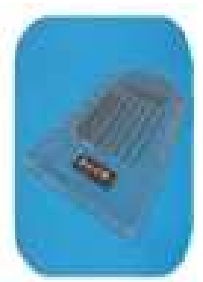

(c)
Fig Image Quality Indicators (a) Plaque hole Type Penetrameter, (b) ASTM Type, (c) Wire Type

Penetrameter

\section{$>$ Radiographic Film}

X-rays films for general radiography consist of an emulsiongelatine containing a radiation sensitive silver halide and a flexible, transparent, blue-tined base. The emulsion is different from those used in other types of photography films to account for the distinct characteristics of gamma rays and $\mathrm{X}$-rays, but X-ray films are sensitive to light. Usually, the emulsion is coated on both sides of the base in layers about 0.0005 inch thick. Putting emulsion on both sides of the base doubles the amount of radiation-sensitive silver halide, and thus increases the film speed. The emulsion layers are thin enough so developing, fixing, and drying can be accomplished in a reasonable time. A few of the films used for radiography only have emulsion on one side which produces the greatest detail in the image. When x-rays, gamma rays or light strike the grains of the sensitive silver halide in the emulsion a change takes place in the physical structure of the grains. This change is of such a nature that it cannot be detected by ordinary physical methods.

\section{A. Film Selection}

The selection of a film when radiographing any particular component depends on a number of different factors. Listed below are some of the factors that must be considered when selected a film and developing a radiographic technique.

1. The composition, shape and size of the part being examined and, in some cases, its weight and location.

2. The type of radiation used, whether x-rays from an x-ray generator or gamma rays from a radioactive source.

3. The kilovoltages available with the x-ray equipment or the intensity of the gamma radiation

4. The relative importance of high radiographic detail o quick and economical results.

Selecting the proper film and developing the optimal radiographic technique usually involves arriving at a balance between a number of opposing factors. For example, if high resolution and contrast sensitivity is of overall importance, a slower and hence finer grained film should be used in place of a faster film.

\section{B. Structure of Film}

The structure of a film consists of four layers and crosssectional view of typical film is shown in figure.

1. Protective Layer ( $1 \mu$ Size)

2. Emulsion Layer (10-15 $\mu$ Size)

3. Base Layer (175 $\mu$ Size)

4. Binding layer or substratum layer

\section{Film Factor}

It is the intensity required to achieve the density value 2.0 (or) the amount of exposure of a given radiation on a film to produce a given film density value 2.0 under specified conditions of processing is called Film Factor. A film with lower film factor value is faster than the one with a higher film factor value.

\section{$>$ Film Processing}

The film on exposure to the $\mathrm{X}$ or gamma radiation a latent image is formed in the x-ray film. The main purpose of film processing is it converts this invisible latent image formed by x-ray or gamma radiation on the film to a visible and permanent image.

Film during process in undergoes five stages.

$>$ Development: creation of the visible image by using a developer

$>$ Stop bath: removal of excess developer solution and stopping f development

Fixation: removal of unwanted, unexposed silver halide and making image permanent

Washing: removal of unwanted fixation products.

Drying: removal of excess or unwanted water.

\section{Latent Image Formation}

On exposure of film to $\mathrm{X}$ and gamma radiation, silver bromide in film is converted to metallic silver. A series of changes occur on exposure of film to gamma or visible radiation. The series of changes is Energy absorption.

- Energy release.

- Electron trapping.

- Silver ion absorption.

- Metallic silver formation.

\section{$>$ Radiograph Interpretation- Welds}

Interpretation of radiographs takes place in three steps, which are (1) detection, (2) interpretation, (3) evaluation. All of these steps make use of the radiographer visual activity. Visual activity is the ability to resolve a spatial pattern in an image. The ability of an individual to detect discontinuities in radiography is also affected by the lighting condition in the place of viewing, and the experience level for recognizing various features in the image. Discontinuities are interpretations in the typical structures of a material. These interpretations may occur in the base metal, weld material or eat effected zones. Discontinuities, which do not meet the requirements of the codes or specification used to invoke and control an inspection.

\section{Radiography Testing}

\section{Apparatus Used}

X-ray tube Cassette (contains film and lead sheets) Dosimete, Dark room, Illuminator. 


\section{Procedure}

Film:

D4 film was selected for X-ray radiography followed by placing between the two metallic foil screens; these are inserted into film cassette. Cassette was placed a side.

\section{Equipment arrangement:}

The X-Ray Voltage and current parameters are selected as $120 \mathrm{Kv}$ and $3 \mathrm{~mA}$ respectively SFD and exposer time are calculated by the following formulae's $\mathrm{SFD}=\mathrm{t}(1+(\mathrm{f} / \mathrm{Ug}))$

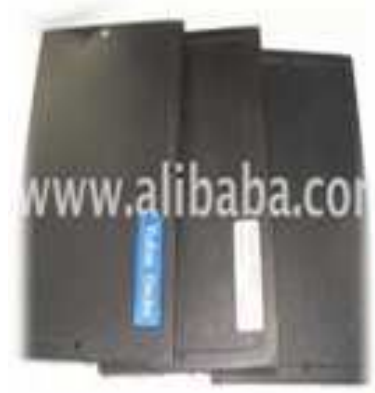

(a)

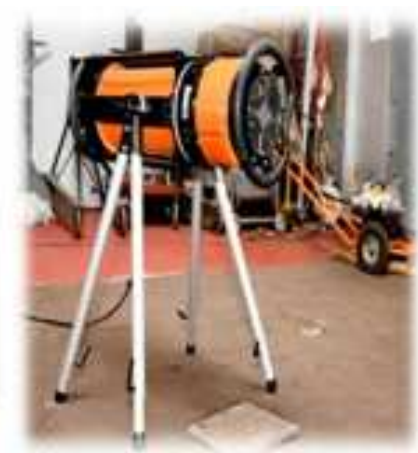

(b)
Fig. (a) cassette, (b) Radiography arrangement

The Penetrameter placed in the sample and the film was placed under the sample

The sample is placed with distance of $15.1 \mathrm{~cm}$ from the X-Ray source

The power is switched on and the X-Rays are exposed on the sample with 3sec calculated time after the exposure time the cassette is taken into the dark room.

\section{Film processing:}

> Developing: creation of visible image by using developer and the developer consisting of four major components metal, hydroquinone and phenidone with react with silver bromide. The

$>$ Stop bath: after developing the image is already existence and remaining process make it permanent the stop bath consist of acetic acid it will gives the density to the film the film is immersed for 5 minutes.

$>$ Fixing: the fixing was consisting of sodium thio sulphate, $\mathrm{Na} 2 \mathrm{SO} 3$, boric acid with water these will fix the film. In this bath the film was immersed for 5 minutes

$>$ Washing: the film is washed by the flowing water for 5 to 10 minutes

Drying: the wet films are dried by blowing a current of hot hair over the film the temperature between $38-40^{\circ}$ C. the film come out dry in 1 or 2 minutes
$>$ Interpretation: After developing the film, we can interpret defects by using illuminator.

\section{Result and Discussion}

\section{Radiography Test Reports}

Five samples of AA 2014 materials were tested by using XRay radiography. Inclusions, undercut, lack of penetration, blow holes and small porosity were detected from the recorded film as shown in fig.

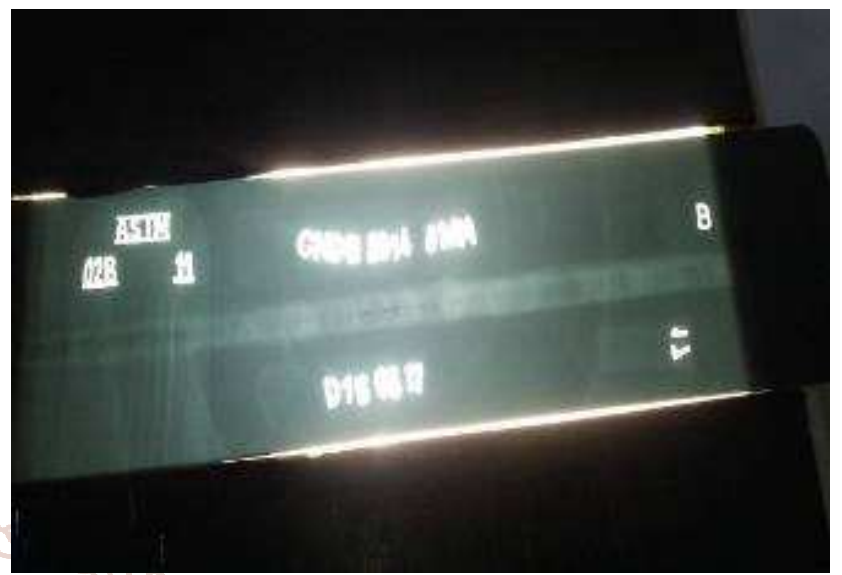

Fig. Radiography Films porosity

\section{CONCLUSION}

X-ray Radiography gave the images of internal defects. Surface defects were detected by penetrant testing and internal defects like inclusions, blow holes, porosity, lack of penetration was detected by Radiography testing. Acoustic Emission was calibrated and standardized with AA2014 samples, shear velocity was determined. Finally, experimented shear velocity was correlated with theoretical shear velocity value.

\section{REFERENCES}

[1] ASTM handbook volume number 17 "Non-Destructive Evaluation and Quality Control"

[2] Ultrasonic Flaw Detection in Metals-banks old field \& Revinding-ILIFEE 1962

[3] Ultrasonic Flaw Detection for Technician's-third edition, June 2004 by S.C. Drury

[4] Hand Book of Non-Destructive Evaluation-Charles Heller

[5] kundu, T. (Ed), (2003), Ultrasonic Non-Destructive Evaluation; Engineering and Biological Material Characterization, CRC Press, USA.

[6] Practical Non-Destructive Testing by Baldev Raj, T. Jayakumar, M. Thavasimuthu 